\title{
Anthropometric, haemodynamic, humoral and hormonal evaluation in patients with incidental adrenocortical adenomas before and after surgery
}

\author{
Giampaolo Bernini, Angelica Moretti, Pietro Iacconi ${ }^{1}$, Paolo Miccoli ${ }^{1}$, Renato Nami ${ }^{2}$, Barbara Lucani ${ }^{2}$ and \\ Antonio Salvetti \\ Department of Internal Medicine and ${ }^{1}$ Department of Surgery, University of Pisa, Pisa, Italy and ${ }^{2}$ Department of Internal Medicine, University of Siena, \\ Siena, Italy \\ (Correspondence should be addressed to Giampaolo Bernini, Department of Internal Medicine, University of Pisa, Via Roma 67, 56100, Pisa, Italy; \\ Email: g.bernini@med.unipi.it)
}

\begin{abstract}
Objective: To compare clinical and humoral parameters before and after surgery in patients with incidental adrenocortical adenomas.

Design: Six patients with subclinical Cushing's syndrome and nine with non-functioning adenomas were investigated before and 12 months after removal of the mass.

Methods: Anthropometric (body weight, body mass index and waist to hip ratio), haemodynamic (blood pressure and heart rate), metabolic (lipids and oral glucose tolerance test (OGTT)), hormonal (cortisol, plasma renin activity, aldosterone, androgens and catecholamines) and bone metabolism (hydroxyproline, parathyroid hormone, osteocalcin and ostase) parameters were evaluated.

Results: In the whole group, a significant decrease in body weight $(69.7 \pm 3.5$ vs $70.8 \pm 3.5 \mathrm{~kg}$, $P<0.03)$, in systolic $(135.3 \pm 5.1$ vs $145.6 \pm 4.9 \mathrm{mmHg}, P<0.009)$ and diastolic $(83.7 \pm 1.9$ vs $91.0 \pm 3.5 \mathrm{mmHg}, P<0.03)$ blood pressure and in glucose levels in response to OGTT $(106.4 \pm 9.6$ vs $127.5 \pm 6.5 \mathrm{mg} / \mathrm{dl}, P<0.05)$ was observed after surgery. All other parameters examined did not change significantly. This trend was also found in both groups separately. Analytical data showed a high frequency of overweight/obesity (66.6\%), hypertension $(66.6 \%)$ and impaired glucose profile $(26.6 \%)$ in our patients, with a greater prevalence of these cardiovascular risk factors in the subclinical Cushing's syndrome group. After surgery, values normalized or improved in eight out of ten hypertensive patients and in three out of four patients with impaired glucose profile.

Conclusions: Solid adrenocortical incidentalomas are associated with some cardiovascular risk factors which may be corrected after removal of the mass. Therefore, surgery may be an appropriate choice in patients with subclinical Cushing's syndrome but also in those with solid non-functioning adenomas and coexistent cardiovascular risk factors.
\end{abstract}

European Journal of Endocrinology 148 213-219

\section{Introduction}

Several reports on asymptomatic incidentally discovered adrenal masses indicate that subclinical Cushing's syndrome is not uncommon, ranging between 5 and $14 \%(1-8)$. Recognition of this disease is important for many reasons. Firstly, it could evolve into overt disease $(3,9,10)$ with the well-known haemodynamic and metabolic consequences. Secondly, in the case of surgical removal of the mass, perioperative cortisol replacement therapy is recommended to avoid the risk of adrenal insufficiency due to suppression of the contralateral normal gland $(3,6,9,11)$. Thirdly, we cannot exclude the possibility that subclinical Cushing's syndrome is responsible for or contributes to the development or maintenance of some haemodynamic or metabolic alterations, typical of the overt form. Accordingly, in the literature there are several reports on associations between subclinical Cushing's syndrome and hypertension, obesity, diabetes or bone metabolism impairment $(3,12-20)$. A similar association was found even in non-functioning adenomas, in which the global cardiovascular risk seems to be higher than in the general population $(6,17,20-24)$. Following these findings, surgery would seem to be a valid therapeutic approach for all solid adrenal incidentalomas.

The aim of our prospective study was to compare anthropometric, haemodynamic and humoral parameters before and after surgery in patients with solid 
adrenocortical incidentalomas, both with subclinical Cushing's syndrome and with non-functioning adenomas.

\section{Subjects and methods}

\section{Patients}

Among patients referred to our Institution for adrenal incidentalomas, six patients with subclinical Cushing's syndrome and nine with solid non-functioning masses were consecutively operated on. In the latter, the removal of the mass was due to mass size over $3.5 \mathrm{~cm}$ in diameter $(n=6)$, radiological features suggestive of malignancy $(n=2)$ and increase in tumour size $(n=1)$. Thus, we studied 15 patients (three males and 12 females) aged from 33 to 71 years (mean age 50.6 years) after obtaining their informed consent to enter this study. Adrenal masses had been detected by ultrasonography and by computed tomography, performed in all cases for unrelated diseases. No patient showed signs and/or symptoms of hormonal hypersecretion, except for hypertension, disturbed glucose tolerance and obesity. Adrenal masses, six right-sided and nine left-sided, ranged in size from 20 to $52 \mathrm{~mm}$ in diameter $(37 \pm 2.7 \mathrm{~mm}$, means \pm s.E. $)$.

Subclinical hypercortisolism was considered in accordance with the recommendations of the National Italian Study Group on Adrenal Tumors: no clinical sign of hormone excess and presence of at least two abnormalities in hypothalamic-pituitary-adrenal function. A necessary condition was failure to achieve plasma cortisol suppression to below $50 \mathrm{ng} / \mathrm{ml}$ by $1 \mathrm{mg}$ dexamethasone (DEX). Other abnormalities included reduced adrenocorticotrophin (ACTH) levels, high urinary free cortisol (UFC), and lack of a circadian rhythm (7). Diagnosis of non-functioning masses was made after exclusion of abnormal secretion of glucocorticoids, catecholamines, androgens or precursors and after exclusion of primary aldosteronism: plasma aldosterone $(\mathrm{ALD})<20 \mathrm{ng} / \mathrm{dl}$, ALD/plasma renin activity (PRA) ratio $<112(95 \%$ upper confidence limit of normal values obtained from 82 patients with essential hypertension) and normal responses to captopril (50 mg os) and saline loading (2 litres saline in $4 \mathrm{~h}$ ) tests. ALD values above $15 \mathrm{ng} / \mathrm{dl}$ after captopril and above $10 \mathrm{ng} / \mathrm{dl}$ after salt loading were considered a typical feature of hyperaldosteronism. The hormonal pattern of the patients with subclinical Cushing's syndrome (four females and two males, mean \pm S.D. age $50.8 \pm 13.2$ years, range $33-71$ years) is shown in Table 1, and that of patients with non-functioning masses (eight females and one male, mean \pm S.D. age $50.5 \pm 9.5$ years, range $33-61$ years) is also shown in Table 1. Except for the hormones related to the pituitary-adrenal axis, none of the other parameters investigated showed any significant differences between the two groups. However, in patients with subclinical Cushing's syndrome we found higher blood pressure and post-oral glucose tolerance test (OGTT) glycaemia, and lower PRA, kalaemia and dehydroepiandrosterone sulphate (DHEA-S) values than in patients with nonfunctioning adenomas, though not to a significant extent (Table 2).

The patients underwent laparoscopic adrenalectomy without post-operative complications. Resected tumours were diagnosed histologically as adrenocortical adenomas in all cases. Post-operative hydrocortisone

Table 1 Hormonal data of patients with subclinical Cushing's syndrome and non-functioning adenomas.

\begin{tabular}{|c|c|c|c|c|c|c|c|c|c|}
\hline \multirow[b]{2}{*}{ Patient number } & \multicolumn{2}{|c|}{$\begin{array}{c}\text { Cortisol } \\
\text { (ng/ml) }\end{array}$} & \multirow[b]{2}{*}{ Circadian rhythm } & \multirow{2}{*}{$\begin{array}{c}\text { UFC } \\
(\mu \mathrm{g} / 24 \mathrm{~h})\end{array}$} & \multirow{2}{*}{$\begin{array}{l}\text { АCTH } \\
(\mathrm{pg} / \mathrm{ml})\end{array}$} & \multirow{2}{*}{$\begin{array}{l}\text { Aldosterone } \\
(\mathrm{ng} / \mathrm{dl})\end{array}$} & \multirow{2}{*}{$\begin{array}{c}\text { PRA } \\
(\mathrm{ng} / \mathrm{ml} \text { per h) }\end{array}$} & \multirow{2}{*}{$\begin{array}{l}\text { Nor-adrenaline } \\
(\mathrm{pg} / \mathrm{ml})\end{array}$} & \multirow{2}{*}{$\begin{array}{c}\text { Adrenaline } \\
(\mathrm{pg} / \mathrm{ml})\end{array}$} \\
\hline & Before & After DEX* & & & & & & & \\
\hline \multicolumn{10}{|c|}{ Cushing's syndrome } \\
\hline 1 & 152 & 118 & Absent & 40 & 6 & 15.8 & 0.20 & 226 & 39 \\
\hline 2 & 208 & 83 & Absent & 77 & 7 & 19.0 & 0.27 & 233 & 58 \\
\hline 3 & 160 & 66 & Absent & 92 & 11 & 19.2 & 0.45 & 382 & 10 \\
\hline 4 & 106 & 102 & Absent & 50 & 8 & 3.9 & 0.33 & 517 & 56 \\
\hline 5 & 155 & 80 & Absent & 72 & 6 & 20.0 & 0.30 & 567 & 63 \\
\hline 6 & 188 & 99 & Absent & 100 & 10 & 8.6 & 0.68 & 159 & 16 \\
\hline \multicolumn{10}{|c|}{ Non-functioning adenoma } \\
\hline 1 & 177 & 16 & Present & 21 & 26 & 14.8 & 0.25 & 453 & 57 \\
\hline 2 & 123 & 32 & Present & 90 & 32 & 5.3 & 0.54 & 221 & 76 \\
\hline 3 & 148 & 15 & Present & 48 & - & 11.5 & 0.22 & 262 & 77 \\
\hline 4 & 199 & 12 & Present & 120 & 19 & 9.1 & 1.13 & 262 & 43 \\
\hline 5 & 112 & 15 & Present & 23 & 21 & 12.9 & 0.17 & 177 & 51 \\
\hline 6 & 152 & 36 & Present & 一 & 17 & 22.0 & 0.33 & 188 & 10 \\
\hline 7 & 232 & 24 & Present & - & 20 & 36.7 & 2.43 & 349 & 10 \\
\hline 8 & 218 & 28 & Present & - & 30 & 16.0 & 1.2 & 413 & 61 \\
\hline 9 & 183 & 35 & Present & 32 & 16 & 18.0 & 1.6 & - & - \\
\hline
\end{tabular}

* DEX (Dexamethasone) $1 \mathrm{mg}$ orally.

Free and total testosterone, androstenedione and $17 \alpha-\mathrm{OH}$-progesterone were normal in all cases. 
Table 2 Clinical data of patients with sub-clinical Cushing's syndrome (SCS) and non-functioning adenomas (NFA). Means \pm S.E.M. are reported.

\begin{tabular}{lrr}
\hline Parameters & SCS $(n=6)$ & NFA $(n=9)$ \\
\hline SBP $(\mathrm{mmHg})$ & $154 \pm 4.95$ & $140 \pm 7.22$ \\
DBP $(\mathrm{mmHg})$ & $98 \pm 4.73$ & $86 \pm 4.39$ \\
Basal glycaemia $(\mathrm{mg} / \mathrm{dl})$ & $92 \pm 6.86$ & $101 \pm 10.0$ \\
Post-OGTT glycaemia $(\mathrm{mg} / \mathrm{dl})$ & $136 \pm 4.52$ & $119 \pm 7.23$ \\
PRA $(\mathrm{ng} / \mathrm{ml} / \mathrm{h})$ & $0.37 \pm 0.07$ & $0.87 \pm 0.25$ \\
Kalaemia $(\mathrm{mEq} / \mathrm{l})$ & $3.7 \pm 0.13$ & $3.9 \pm 0.07$ \\
DHEA-S $(\mu \mathrm{g} / \mathrm{ml})$ & $0.45 \pm 0.08$ & $0.9 \pm 0.34$ \\
\hline
\end{tabular}

SBP and DBP: systolic and diastolic blood pressure.

$P$ values were not significant.

supplement therapy (25-37.5 mg/day) was given (3-5 weeks) to four patients with subclinical Cushing's syndrome and to one patient with a non-functioning adenoma for the occurrence of symptoms of hypoadrenalism.

\section{Evaluation before and after surgery}

Anthropometric, haemodynamic, hormonal and humoral parameters were obtained before and 12 months after the removal of the mass. On both occasions, prior to testing, patients received a saltcontrolled diet (80-100 mmol/day sodium and 60$80 \mathrm{mmol} /$ day potassium) and patients taking drugs (anti-hypertensive or other drugs) suspended medication for at least 2 weeks prior to the study. No women took drugs to prevent osteoporosis before or after surgery. On the test day all patients underwent blood sampling at $0800 \mathrm{~h}$ in fasting and sitting conditions.

Anthropometric and haemodynamic parameters Body weight, body mass index $\left(\mathrm{kg} / \mathrm{m}^{2}\right)$ and waist to hip ratio were evaluated in the morning. To define overweight or obesity, recent International Guidelines were adopted (25). Blood pressure was recorded by mercury sphygmomanometer following recent guidelines (26).

Humoral parameters Urinary excretion of potassium $(\mathrm{mEq})$, sodium $(\mathrm{mEq})$, creatinine $(\mathrm{mg})$ and protein $(\mathrm{g})$ were measured over a $24-\mathrm{h}$ period on 2 consecutive days. Plasma glucose $(\mathrm{mg} / \mathrm{dl})$, total cholesterol (mg/dl), high density lipoprotein (HDL) cholesterol $(\mathrm{mg} / \mathrm{dl})$, triglycerides $(\mathrm{mg} / \mathrm{dl})$, creatinine $(\mathrm{mg} / \mathrm{dl})$, sodium $(\mathrm{mEq} / \mathrm{l})$ and potassium $(\mathrm{mEq} / \mathrm{l})$ were evaluated. The OGTT was also performed: after an overnight fast, subjects were given an oral dose of glucose $(75 \mathrm{~g})$. Plasma for glucose determination was collected at 0 and $120 \mathrm{~min}$. To establish the presence of impaired fasting glucose, impaired glucose tolerance or diabetes, recent International Guidelines were adopted (27).
Hormonal parameters with normal values (n.v.) Twenty-four-hour excretion of UFC (n.v. $<120 \mu \mathrm{g}$ ) and ALD $(\mu \mathrm{g})$ was evaluated, while plasma samples were collected for determinations of cortisol (n.v. = $60-300 \mathrm{ng} / \mathrm{ml}$ ), ACTH (n.v. $=9-52 \mathrm{pg} / \mathrm{ml}$ ), PRA $(\mathrm{ng} / \mathrm{ml} / \mathrm{h})$, ALD $(\mathrm{ng} / \mathrm{dl})$, DHEA-S $\quad(\mathrm{n} . \mathrm{v} .=0.3-4.3$ $\mu \mathrm{g} / \mathrm{ml}$ ), $\quad 17 \alpha-\mathrm{OH}$-progesterone (n.v. $=0.15-3.4 \mathrm{ng}$ / $\mathrm{ml}$ ), free testosterone (n.v. $<3.6 \mathrm{pg} / \mathrm{ml}$ for females and n.v. $=10-40 \mathrm{pg} / \mathrm{ml}$ for males), total testosterone (n.v. $=0.1-1.0 \mathrm{ng} / \mathrm{ml}$ for females and n.v. $=$ $3.0-10 \mathrm{ng} / \mathrm{ml}$ for males), androstenedione (n.v. = $0.2-3.1 \mathrm{ng} / \mathrm{ml}$ ), noradrenaline (n.v. $<600 \mathrm{pg} / \mathrm{ml}$ ) and adrenaline (n.v. $<80 \mathrm{pg} / \mathrm{ml}$ ). In addition, an overnight DEX suppression test was performed with oral administration of $1 \mathrm{mg}$ DEX at $2300 \mathrm{~h}$ and measurement of plasma cortisol levels on the following day.

Bone metabolism parameters Urinary excretion of calcium (mEq), phosphorus (mEq) and hydroxyproline (HOP; mg) was measured over a 24-h period. Plasma samples for calcium (mg/dl), phosphorus (mg/dl), alkaline phosphatase (U/l), parathyroid hormone (PTH; $\mathrm{pg} / \mathrm{ml})$, osteocalcin $(\mathrm{ng} / \mathrm{ml})$ and ostase $(\mathrm{pmol} / \mathrm{ml})$ were collected.

\section{Assays}

Plasma and urinary samples were collected, centrifuged and stored at $-70^{\circ} \mathrm{C}$ until assayed. Serum total calcium, phosphorus, creatinine, glucose, sodium, potassium and alkaline phosphatase total activity were determined by a multichannel autoanalyzer. Total and HDL cholesterol and triglycerides were evaluated using an enzymatic method (Menarini, Florence, Italy). Urinary HOP was assessed, after reverse phase high-performance liquid chromatography, fluorometrically by kits from Bio-Rad Laboratories, Inc. (Segrate, Italy; intra- and interassay coefficients of variation (CV), $6.6 \%$ and $12.3 \%$ respectively).

All hormones were assayed in duplicate and in the same run using specific commercial radioimmunoassay kits, except for intact PTH (two-site immunochemilumimometric assay; Chiron Diagnostics, East Walfale, MA, USA) and catecholamines (high-performance liquid chromatography). Intra- and interassay $\mathrm{CV}$ values of the hormones were as follows: DHEA-S (Radim, Rome, Italy), $6.8 \%$ and $8.1 \% ; 17 \alpha-\mathrm{OH}-$ progesterone (ICN Biomedicals, Costa Mesa, CA, USA), $9.4 \%$ and $11.8 \%$; androstenedione (Sorin, Saluggia, Italy), $7.1 \%$ and $10.8 \%$; cortisol (Immunoteck International, Marseille, France), 5.7\% and 6.6\%; ACTH (Nichols Institute Diagnostics, San Juan Capistrano, CA, USA), 3.1\% and 7.3\%; ALD (DiaSorin, Saluggia, Italy), 9.7\% and 11.5\%; PRA (DiaSorin), $7.6 \%$ and 9.1\%; osteocalcin (Stillwater, Minnesota, USA), $8.2 \%$ and 10\%; ostase (Beckman Coulter, CA, USA), 6.7\% and 8.1\%; free testosterone (Diagnostic Systems 
Laboratories, Inc. Webster, TX, USA), 5.0\% and 8.3\%; total testosterone (Medical System, Genova, Italy), 6.0 and $7.8 \%$, respectively.

\section{Statistics}

All data are expressed as the means \pm S.E.M. A nonparametric test (Wilcoxon rank test) was used to analyze intra-group variations before and after surgery and to compare the two groups. $P$ values of less than 0.05 were considered significant.

\section{Results}

In all patients with subclinical Cushing's syndrome cortisol response to DEX was restored after removal of the mass $(8.8 \pm 1.3$ vs $151.6 \pm 12.7 \mathrm{ng} / \mathrm{ml}, P<0.0001)$. In patients with non-functioning adenomas, the normal cortisol suppression to DEX before surgery was maintained after the operation $(9.4 \pm 2.3$ vs $179.3 \pm$ $16.3 \mathrm{ng} / \mathrm{ml}, P<0.0001)$.

In the whole group, a significant decrease in body weight $(69.7 \pm 3.5$ vs $70.8 \pm 3.5 \mathrm{~kg}, P<0.02)$, systolic $(135.3 \pm 5.1$ vs $145.6 \pm 4.9 \mathrm{mmHg}, P<0.01)$ and diastolic $(83.7 \pm 1.9$ vs $91.0 \pm 3.5 \mathrm{mmHg}, P<0.05)$ blood pressure and in glucose levels in response to OGTT (106.4 \pm 9.6 vs $127.5 \pm 6.5 \mathrm{mg} / \mathrm{dl}, P<0.05)$ as well as an increase in plasma potassium $(4.2 \pm 0.13 \mathrm{vs}$ $3.8 \pm 0.15 \mathrm{mEq} / \mathrm{l}, P<0.002)$ were observed after surgery. All other parameters examined, including sex hormone levels, ALD and PRA values showed no significant change (Table 3). This pattern was also found in both groups separately, even though the reduction in body weight $(69.5 \pm 4.9$ vs $71.6 \pm 4.8 \mathrm{~kg}$, $P<0.01)$ and in systolic blood pressure $(130.8 \pm 6.4$ vs $140.2 \pm 7.2 \mathrm{mmHg}, P<0.05)$ reached statistical significance only in non-functioning adenomas.

Interesting findings were obtained from the analytical data. A high prevalence of overweight/obesity $(66.6 \%)$, hypertension $(66.6 \%)$ and glucose intolerance/diabetes $(26.6 \%)$ was found in the whole group with adrenal incidentalomas. In particular, in subclinical Cushing's syndrome, four out of six patients were overweight, five had hypertension, two showed

Table 3 Sex hormone, PRA and aldosterone values before and after surgery in the whole group. Means \pm S.E.M. are reported.

\begin{tabular}{lcc}
\hline Parameters & Before & After \\
\hline PRA $(\mathrm{ng} / \mathrm{ml}$ per $\mathrm{h})$ & $0.62 \pm 0.18$ & $1.15 \pm 0.23$ \\
Plasma aldosterone $(\mathrm{ng} / \mathrm{dl})$ & $15.52 \pm 2.08$ & $15.32 \pm 2.62$ \\
Urinary aldosterone $(\mu \mathrm{g} / 24 \mathrm{~h})$ & $13.13 \pm 1.85$ & $13.31 \pm 2.4$ \\
Free testosterone $(\mathrm{pg} / \mathrm{ml})$ & $2.8 \pm 0.15$ & $2.65 \pm 0.18$ \\
Total testosterone $(\mathrm{ng} / \mathrm{ml})$ & $0.74 \pm 0.27$ & $0.38 \pm 0.11$ \\
DHEA-S $(\mu \mathrm{g} / \mathrm{ml})$ & $0.70 \pm 0.23$ & $0.45 \pm 0$ \\
Androstenedione $(\mathrm{ng} / \mathrm{ml})$ & $1.14 \pm 0.25$ & $0.89 \pm 0.19$ \\
\hline
\end{tabular}

$P$ values were not significant. impaired fasting glucose, four had low osteocalcin and three elevated PTH levels. After surgery, two patients showed normalized and another two improved blood pressure (Fig. 1a), and previously impaired fasting glucose was restored in one case. Interestingly, all these patients had shown adrenal insufficiency after surgery with consequent hydrocortisone replacement therapy. No modification was found in the overweight patients or in those with altered osteocalcin and PTH values. In non-functioning adenomas, six out of nine patients were overweight or obese, five were hypertensive, three had dyslipidaemia, two showed diabetes and three had low osteocalcin. After surgery, three patients showed normalized and one improved blood pressure (Fig. 1b), and the disappearance of diabetes was found in the two patients with this metabolic disorder. No change was observed in the patients with dyslipidaemia, overweight or obesity and with low osteocalcin levels. Thus, removal of the mass normalized or improved blood pressure in eight out of ten patients $(80 \%)$ and the glucose profile in three out of four patients $(75 \%)$.

\section{Discussion}

The therapeutic choice in solid adrenal incidentalomas is still under debate. For adrenal masses of large dimensions $(>3.5-4.0 \mathrm{~cm})$ and/or with radiological features of malignancy and for hyperfunctioning masses, the surgical approach is commonly recommended $(7,28$, 29). In contrast, doubts exist for patients with subclinical Cushing's syndrome and for those with nonfunctioning, apparently benign, small adenomas. According to some authors $(20,30,31)$, the rarity with which subclinical Cushing's syndrome evolves into the overt form and the persistent functional inactivity of non-functioning adenomas suggests that these patients should be followed only with clinical and radiological examinations. Other authors claim that the high prevalence of cardiovascular risk factors in patients with adrenal masses, both sub-clinical Cushing's (3, 12-20) and non-functioning tumours $(6,17,20-24)$, requires surgical treatment, especially in patients with hypertension, obesity, glucose intolerance or diabetes. Accordingly, an improvement in cardiovascular risk factors after surgery has been occasionally reported in patients with adrenal incidentalomas $(11,20,24,32)$. The tendency towards the surgical approach is further encouraged by the finding that the new laparoscopic adrenalectomy technique has shown superiority over conventional open adrenalectomy in terms of post-operative recovery, hospital days and overall cost (33).

Our investigation was prospective and was planned to consecutively include patients with solid adrenal masses, independently of the presence or absence of cardiovascular risk factors. The follow-up was fairly 

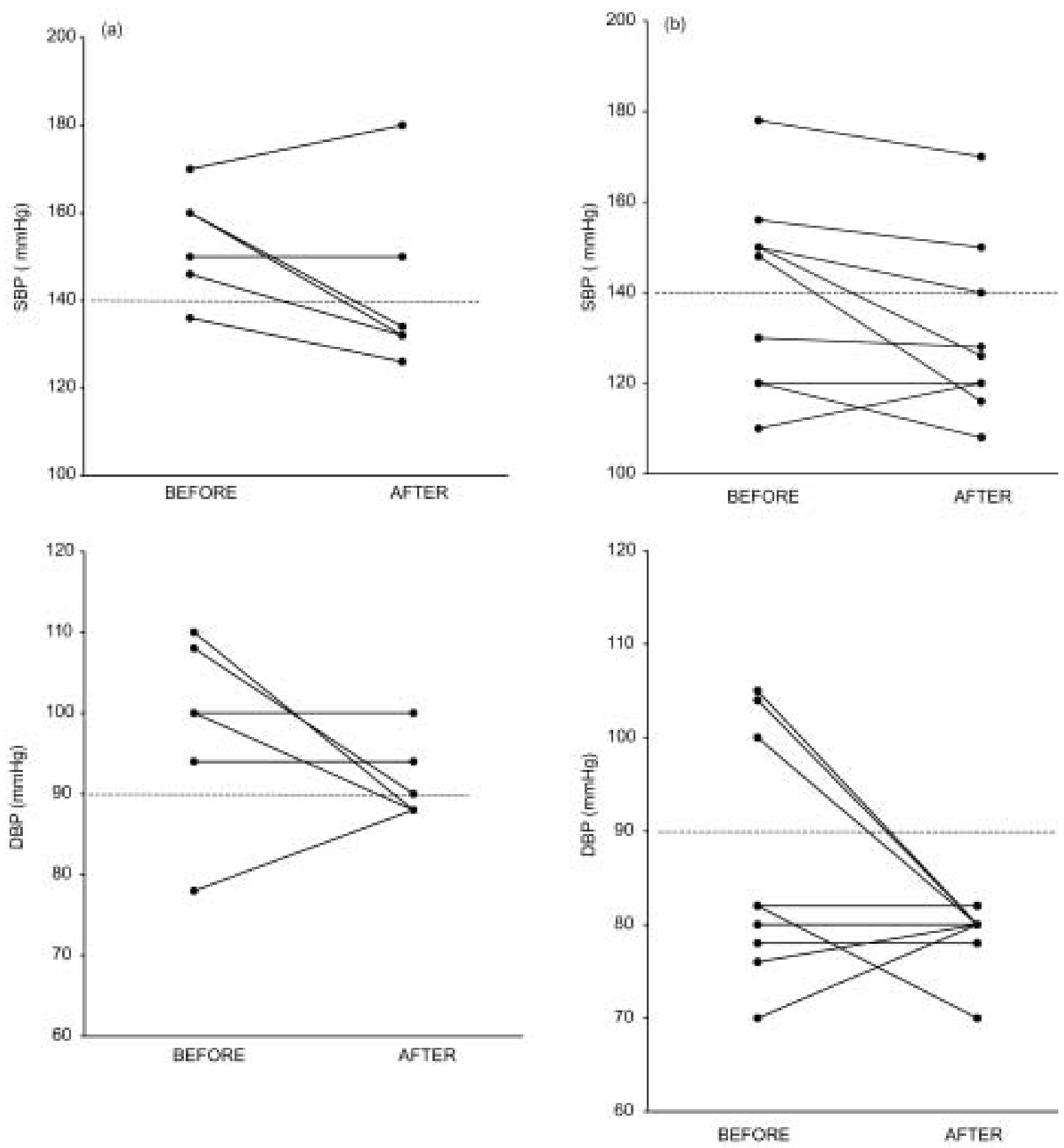

Figure 1 Individual values of systolic (SBP) and diastolic blood pressure (DBP) before and after surgery in patients with (a) subclinical Cushing's syndrome and (b) non-functioning adenomas.

prolonged to monitor possible haemodynamic and metabolic modifications. Finally, at variance with other published data $(10,20,24)$, only in our study the gold standard was to evaluate the impact of surgery on several cardiovascular risk factors in patients with adrenal masses. Unfortunately, the limited number of patients recruited in our study does not allow a clear-cut evaluation of the prevalence of cardiovascular risk factors in adrenal incidentalomas. Therefore we are aware that our data need to be considered as preliminary results and confirmed in larger series of patients.

Despite these reservations, the present data confirm the high prevalence of hypertension, obesity and metabolic disorders in well-ascertained cases of subclinical 
Cushing's syndrome, indicating, in addition, that after removal of the adrenal mass some cardiovascular risk factors are reduced and this reduction is maintained for a considerable time. An interesting and unexpected finding of our results was that even in patients with non-functioning adenomas the prevalence of cardiovascular risk factors is elevated and some factors (hypertension and diabetes) normalized after surgery. It is difficult to establish whether there is a pathophysiological link between removal of the adrenal mass and normalization of cardiovascular risk factors in such patients. Only prospective studies in groups of patients with adrenocortical adenomas randomized for surgery or for medical follow-up, and studies on patients operated on for incidentaloma that turn out to be nonadrenal masses might offer more detailed information. However, since a relationship between cortisol and cardiovascular risk factors is well-known in Cushing's syndrome, we can hypothesize a similar inter-relationship in subclinical Cushing's syndrome, in which an impairment of the hypothalamic-pituitary-adrenal axis is present, albeit more qualitative than quantitative. Indirect proof of this assumption is derived from our finding that the patients with subclinical Cushing's syndrome who experienced adrenal insufficiency after surgery (for adrenal contralateral suppression by the hyperfunctioning adenoma) obtained greater benefits, at least for blood pressure. In contrast, the link between surgery and cardiovascular risk improvement is apparently inexplicable in non-functioning adenomas, even though the accumulation in precursors of the glucocorticoid and mineralcorticoid pathways (34-36) may have a possible role. However, an improvement of post-surgery lifestyle may also be responsible for the reduction in some cardiovascular risk factors.

Data on bone metabolism in adrenal incidentalomas are discordant, with reported normal (37) or reduced (38) bone mineral density. As far as humoral markers are concerned, bone apposition has been constantly shown to be reduced $(38-40)$ while data on markers of bone resorption are conflicting $(39,40)$. Our results showed that calcium-phosphorus metabolism and markers of bone resorption were normal while osteocalcin was reduced in some patients in both groups, with a picture of secondary hyperparathyroidism in subclinical Cushing's syndrome. However, after surgery no improvement was found in our study, although 12 months follow-up may be too short a time to observe modifications in bone parameters.

In conclusion, we found that adrenal incidentalomas, namely those with subclinical Cushing's syndrome, are associated with some cardiovascular risk factors which may be corrected by removal of the mass. Therefore, if our results are confirmed on more numerous patients, laparoscopic surgery may be preferred not only in patients with subclinical Cushing's syndrome but also in those with solid non-functioning adenomas and coexistent cardiovascular risk factors.

\section{References}

1 Mantero F, Masini AM, Opocher G, Giovagnetti M \& Arnaldi G. Adrenal incidentaloma: an overview of hormonal data from the National Italian Study Group. Hormone Research $1997 \mathbf{4 7}$ 284-289.

2 Barzon L, Scaroni C, Sonino N, Fallo F, Gregianin M, Macri' C et al. Incidentally discovered adrenal tumors: endocrine and scintigraphic correlates. Journal of Clinical Endocrinology and Metabolism $19988355-62$.

3 Reincke M, Nieke J, Krestin GP, Saeger W, Allolio B, Winkelmann W et al. Preclinical Cushing's syndrome in adrenal 'incidentalomas': comparison with adrenal Cushing's syndrome. Journal of Clinical Endocrinology and Metabolism 199275 826-832.

4 Terzolo M, Osella G, Ali’ A, Borretta G, Cesario F, Paccotti P et al. Subclinical Cushing's syndrome in adrenal incidentalomas. Clinical Endocrinology $1998 \mathbf{4 8} 89-97$.

5 Fernandez-Real JM, Richart-Engel WR \& Simo' R. Preclinical Cushing' syndrome: report of three cases and literature review. Hormone Research 199441 230-235.

6 Osella G, Terzolo M, Borretta G, Magro G, Ali’ A, Piovesan A et al. Endocrine evaluation of incidentally discovered adrenal masses (incidentalomas). Journal of Clinical Endocrinology and Metabolism $1994791532-1539$.

7 Mantero F, Terzolo M, Arnaldi G, Osella G, Masini AM, Ali’ A et al. A survey on adrenal incidentaloma in Italy. Journal of Clinical Endocrinology and Metabolism 200085 637-644.

8 Sworczak K, Babniska A, Stanek A, Lewczuk A, SiekierskaHellmann M, Blaut K et al. Clinical and histopathological evaluation of the adrenal incidentaloma. Neoplasma $2001 \mathbf{4 8} 221-226$.

9 McLeod M, Thompson NW, Gross M, Bendeson AG \& Bendeson L. Sub-clinical Cushing's syndrome in patients with adrenal gland incidentalomas. Pitfalls in diagnosis and management. American Surgery $1990 \mathbf{5 6} 398-403$.

10 Barzon L, Scaroni C, Sonino N, Fallo F, Paoletta A \& Boscaro M. Risk factors and long-term follow-up of adrenal incidentalomas. Journal of Clinical Endocrinology and Metabolism $1999 \mathbf{8 4}$ 520-526.

11 Ambrosi B, Peverelli S, Passini E, Re T, Ferrario R, Colombo P et al. Abnormalities of endocrine function in patients with clinically 'silent' adrenal masses. European Journal of Endocrinology 1995 $132422-428$.

12 Kobayashi S, Seki T, Nonomura Kgotoh T, Togashi M \& Koyanagi T. Clinical experience of incidentally discovered adrenal tumor with particular reference to cortical function. Journal of Urology $1993 \mathbf{1 5 0} 8-12$.

13 Ambrosi B, Passini E, Re T \& Barbetta R. The clinical evaluation of silent adrenal masses. Journal of Endocrinological Investigation 199720 90-107.

14 Hensen J, Buhl M, Bahr V \& Oelkers W. Endocrine activity of the 'silent' adrenocortical adenoma is uncovered by response to corticotropin-releasing hormone. Klinisch Wochenschrift 1990 $68608-614$.

15 Tsagarakis S, Roboti C, Kokkoris P, Vasiliou V, Alevizaki C \& Thalassinos N. Elevated post-dexamethasone suppression cortisol concentrations correlate with hormonal alterations of the hypothalamo-pituitary adrenal axis in patients with adrenal incidentalomas. Clinical Endocrinology 199849 165-171.

16 Osella G, Terzolo M, Reimondo G, Piovesan A, Pia A, Termine A et al. Serum markers of bone and collagen turnover in patients with Cushing's syndrome and in subjects with adrenal incidentalomas. Journal of Clinical Endocrinology and Metabolism 199782 3303-3307.

17 Fernandez-Real JM, Engel WR, Simo R, Salinas I \& Webb SM. Study of glucose tolerance in consecutive patients harbouring incidental adrenal tumors. Study Group of Incidental Adrenal Adenoma. Clinical Endocrinology 199849 53-61.

18 Sartorio A, Conti A, Ferrero S, Giambone S, Re T, Passini E et al. Evaluation of markers of bone and collagen turnover in patients with active and preclinical Cushing's syndrome and in patients 
with adrenal incidentaloma. European Journal of Endocrinology 1998138 146-152.

19 Huiras CM, Pelhing GB \& Caplan RH. Adrenal insufficiency after operative removal of apparently non-functioning adrenal adenomas. Journal of the American Medical Association 1989261 894-898.

20 Rossi R, Tauchmanova L, Luciano A, Di Martino M, Battista C, Del Viscovo L et al. Subclinical Cushing's syndrome in patients with adrenal incidentaloma: clinical and biochemical features. Journal of Clinical Endocrinology and Metabolism $2000 \mathbf{8 5}$ $1440-1448$.

21 Gomibuchi T. Endocrinological and imaging analyses of adrenal incidentaloma with hypertension and/or diabetes mellitus. Folia Endocrinologica $1994 \mathbf{7 0} 941-950$.

22 Reincke M, Fasnachat M, Vath S, Mora P \& Allolio B. Adrenal incidentalomas: a manifestation of the metabolic syndrome? Endocrine Research 199622 757-761.

23 Hashimoto S, Midorikawa S, Sanada H \& Watanabe T. SSPG titer is diagnostic marker for adrenocortical adenoma in patients with non-functioning adrenal incidentaloma. Biomedicine and Pharmacotherapy $2000 \mathbf{5 4}$ 175-177.

24 Midorikawa S, Sanada H, Hashimoto S, Suzuki T \& Watanabe T. The improvement of insulin resistance in patients with adrenal incidentaloma by surgical resection. Clinical Endocrinology 2001 54 797-804.

25 NHLBI Obesity Education Initiative. The Practical Guide Identification, Evaluation, and Treatment of Overweight and Obesity in Adults. NIH Publication Number 00-4084 October 2000.

26 World Health Organization, International society of hypertension guidelines for the management of hypertension. Journal of Hypertension $199917151-183$.

27 The American Association of Clinical Endocrinologists Medical Guidelines for the Management of Diabetes Mellitus: the AACE system of intensive diabetes self-management - 2000 update. Endocrine Practice 20006 42-67.

28 Barzon L \& Boscaro M. Diagnosis and management of adrenal incidentalomas. Journal of Urology 2000163 398-407.

29 Brunt LM \& Moley JF. Adrenal incidentaloma. World Journal of Surgery 200125 905-913.

30 Siren J, Tervahartiala P, Sivula A \& Haapiainen R. Natural course of adrenal incidentalomas: seven-year follow-up study. World Journal of Surgery $2000 \mathbf{2 4} 579-582$.

31 Grossrubatscher E, Vignati F, Possa M \& Loli P. The natural history of incidentally discovered adrenocortical adenomas: a retro- spective evaluation. Journal of Endocrinological Investigation 2001 24 846-855.

32 Morioka M, Fujii T, Matsuki T, Jo Y, Kobayashi T, Tanaka H et al. Preclinical Cushing's syndrome: report of seven cases and a review of the literature. International Journal of Urology 20007 126-132.

33 Smith CD, Weber CJ \& Amerson JR. Laparoscopic adrenalectomy: new gold standard. World Journal of Surgery 199923 389-396.

34 Terzolo M, Osella G, Ali' A, Borretta G, Magro GP, Termine A et al. Different pattern of steroid secretion in patients with adrenal incidentaloma. Journal of Clinical Endocrinology and Metabolism 1996 $81740-744$.

35 Morioka M, Ohashi Y, Komatsu F, Sawada K, Ebara S, Ohashi T et al. Preclinical Cushing's syndrome: report of four cases and analysis of steroid contents in adenomas. Hormone Research $199646117-123$

36 Reincke M. Steroid secretion in patients with adrenal incidentalomas. Journal of Clinical Endocrinology and Metabolism $1996 \mathbf{8 1}$ $3811-3812$.

37 Osella G, Reimondo G, Peretti P, Ali’ A, Paccotti P, Angeli A et al. The patients with incidentally discovered adrenal adenoma (incidentaloma) are not at increased risk of osteoporosis. Journal of Clinical Endocrinology and Metabolism 200186 604-607.

38 Torlontano M, Chiodini I, Pileri M, Guglielmi G, Cammisa M, Modoni S et al. Altered bone mass and turnover in female patients with adrenal incidentaloma: the effect of subclinical hypercortisolism. Journal of Clinical Endocrinology and Metabolism $1999 \mathbf{8 4}$ $2381-2385$.

39 Osella G, Terzolo M, Reimondo G, Piovesan A, Pia A, Termine A et al. Serum markers of bone and collagen turnover in patients with Cushing's syndrome and in subject with adrenal incidentalomas. Journal of Clinical Endocrinology and Metabolism $1997 \mathbf{8 2}$ 3303-3307.

40 Sartorio A, Conti A, Ferrero S, Giambona S, Re T, Passini E et al. Evaluation of markers of bone and collagen turnover in patients with active and preclinical Cushing's syndrome and in patients with adrenal incidentaloma. European Journal of Endocrinology 1998138 146-152.

Received 16 May 2002

Accepted 21 October 2002 